\title{
Criando gênero: o discurso sobre criação de meninos e meninas na autoajuda de aconselhamento parental
}

\author{
Mayka Castellano
}

Universidade Federal Fluminense, Niterói, Rio de Janeiro, Brasil

\section{Resumo}

Neste artigo, analiso o discurso sobre identidade de gênero apresentado nos livros Criando meninos(2014) e Criando Meninas (2015), de Steve Biddulph, clássicos da autoajuda de aconselhamento parental. Amparada na análise de discurso de inspiração pósestruturalista, investigo de que modo o gênero aparece nas formulações desses livros e de que forma tais ideias refletem expectativas e inquietações culturais a respeito da criação dos filhos na contemporaneidade, levando em consideração os respectivos papéis de gênero em uma sociedade marcada pelo binarismo e pela heteronormatividade.

\section{Palavras-Chave}

Identidade de gênero. Autoajuda. Análise de discurso.

\section{Introdução}

"Ninguém nasce mulher, torna-se", já afirmava em 1949 Simone de Beauvoir (1967, p. 9). A frase ajudaria, anos mais tarde, a conformar o que ficou conhecido como a Segunda Onda do Movimento Feminista, uma das responsáveis por ratificar a importância do componente cultural nas reflexões sobre papéis de gênero. A hoje ubíqua declaração representa uma ideia bastante difundida e aceita, no campo das ciências humanas e sociais, sobre os aspectos cultural, histórico e geográfico dos sentidos que atribuímos à noção do que configura, afinal, "ser uma mulher". Ou seja, ser uma mulher não é algo que nos é dado simplesmente pela designação sexual feita no ato do nascimento, mas um complexo conjunto de características composto por alguns atributos que são da natureza, mas, sobretudo, por aqueles que provêm dos elementos culturais e dos sentidos compartilhados socialmente.

No senso comum, no entanto, temos provas recorrentes de que tais concepções ainda estão longe de serem recebidas com tranquilidade. Associada ao que atualmente é conhecido 
como "Ideologia de gênero" por alas mais conservadoras da sociedade brasileira, fortemente amparadas em um discurso religioso de fundo amiúde oportunista, a percepção do gênero como um construto social é apontada como mais uma estratégia "esquerdista" para derrubar os valores morais, a tradição e a família. O discurso articulado é bastante simples, talvez simplório: homem é homem, mulher é mulher, e os critérios para tal designação também são apresentados de forma direta: homem é quem tem pênis; mulher, quem tem vagina, embora tal tipo de dedução possa facilmente ser abalada pela própria natureza, que por vezes gera indivíduos com características genéticas ambíguas, atualmente chamados de intersexo'. Qualquer ideia dissonante passa, então, a ser compreendida como parte de um grande projeto ideológico identificado sobretudo quando abordado a partir de práticas educacionais ou que de alguma forma envolvam crianças.

Um exemplo bastante recente e, na mesma medida, sintomático do tipo de discussão que vem sendo suscitada a respeito das identidades de gênero pôde ser notada nas reações a uma matéria ${ }^{2}$ veiculada pelo dominical Fantástico em 08 de outubro de 2017. O tema era a opção de uma escola do Rio de Janeiro por não mais separar os brinquedos infantis por gênero, deixando-os à vista e ao alcance de todos os pequenos, sem nenhum tipo de distinção. A matéria começa com a entrevista de um casal que cria seus dois meninos com a preocupação de oferecer aos filhos todas as possibilidades de brincadeiras, sejam elas com carrinhos ou bonecas, segue com depoimentos de especialistas (um psiquiatra da USP, uma professora do Departamento de Estudos de Gênero e Feminismo da UFBA e a diretora da supracitada escola carioca), enquanto exibe algumas cenas de meninos dançando balé e meninas jogando futebol.

O tom da matéria, claramente elogioso às iniciativas analisadas, não passou despercebido por parte do público. Na página do programa no portal G1, o vídeo recebeu muitos comentários. Dentre os que receberam mais curtidas, estavam aqueles que relacionavam diretamente a matéria (que tratava da relação entre brinquedos e papéis de gênero) à homossexualidade, embora isso tenha tão-somente em muitas possíveis conjugações (QUEIROZ, 2016).

2 Disponível em: http://g1.globo.com/fantastico/noticia/2017/10/escola-do-rio-elimina-distincao-entre-brinquedos-demenina-ou-de-menino.htmlAcesso em: 15/10/2017. 
tangenciado a reportagem: "Tem tanta coisa importante para a Sociedade, e a globo quer empurrar garganta abaixo essa porcaria de assunto achando que o povo não valoriza a Família. E essa escola vai produzir muitos problemas no futuro"; "É a globo a todo vapor para acabar com a dignidade humana.... E depois que farão?"; "Isso e um absurdo, sei que não vai ser publicado mas o certo é que estão querendo a todo custo fazer nos acharmos que isso e certo. (...) sobre sexualidade isso tem que ser ensinado dentro de casa pelos pais, menino é menino e menina é menina, na bíblia não fala que Deus fez uma coluna do MEıo. Então isso é errado" (sic); "Qual o objetivo de uma TV querer destruir a maior instituição mais antiga do mundo? Se Deus tivesse feito dois homens, não haveria população no mundo" (sic) são alguns exemplos de comentários que receberam mais de 300 curtidas.

No mesmo dia, o Fantástico exibiu uma longa matéria sobre intolerância religiosa e censura na arte. $\mathrm{O}$ tratamento dessas três temáticas no mesmo dia rendeu uma forte repercussão negativa nas redes sociais. No Twitter, a hashtag \#GloboLixo ${ }^{3}$ ficou entre as mais citadas durante a exibição do programa e ao longo dos dias seguintes. A intensa reação contrária ao tratamento da relação entre brinquedos e gênero mostra quão potente e difundido é o dispositivo de poder que age sobre os corpos e as definições do que seja correto e adequado em termos de sexualidade e de gênero (FOUCAULT, 1988). O fato de apontarmos o caráter de construto social de um fenômeno como esse não significa, como está claro, relativizar seu peso social, sua predominância no senso comum. Neste artigo, parto da percepção de que ideias conservadoras a respeito do binarismo sexual e de seus correlatos papéis estão fortemente inseridas em um imaginário cultural formado, também, a partir de práticas e artefatos típicos da cultura midiática. Para construir meu argumento, analiso ${ }^{4}$ dois livros de autoajuda voltados para a criação de filhos, Criando meninos e Criando meninas, ambos do australiano Steve Biddulph. Os livros são best-sellers, já venderam mais de 4 milhões de cópias ao redor do mundo e foram publicados em 31 idiomas ${ }^{5}$. No Brasil, estão em sua terceira edição pela Editora Fundamento.

3 http://www.huffpostbrasil.com/2017/10/10/como-reportagens-sobre-arte-e-genero-no-fantastico-geraram-uma-ondade-boicote-a-globo_a_23238502/

4. $\mathrm{Na}$ análise dos livros para este artigo, assim como em minha pesquisa sobre autoajuda como um todo, lanço mão da análise de discurso de inspiração pós-estruturalista, que privilegia o conteúdo e o contexto da linguagem e não sua estrutura. Entendo, portanto, a ideia de discurso a partir das relações de poder específicas, historicamente constituídas, que ele engendra e das noções particulares de verdade que ele invoca. 


\section{A cultura da autoajuda}

A autoajuda é, já há pelo menos três décadas, um dos segmentos editoriais de maior sucesso no Brasil e no mundo. A quantidade e a variedade de títulos do gênero disponíveis nas livrarias brasileiras impressionam. Mais do que um filão literário, no entanto, a autoajuda se tornou uma espécie de ethos, uma representação de aspectos morais e estéticos valorativos de uma determinada cultura (GEERTZ, 1978), e é nesse sentido que trabalho essa temática a partir da ideia de "cultura da autoajuda" (CASTELLANO, 2018).

A autoajuda consolidou-se como um manancial de best-sellers no mercado editorial, e os aspectos que aparecem como suscetíveis à sua intervenção variam de forma espetacular. De consultores de moda a médicos oncologistas, os peritos em múltiplos domínios da vida humana proliferam não só nos livros mas também nos demais meios de comunicação e estabelecem diretrizes "confiáveis" para ajudar os sujeitos a enriquecer, empreender, casar, vestir-se, comer, decorar a casa, cuidar da saúde, da beleza, da autoestima, da carreira, dos animais de estimação, a fazer amigos, economizar dinheiro, ficar milionário, virar youtuber, emagrecer, engordar e mais uma série de questões subjetivas, como tornar-se mais assertivo, responsável, corajoso, confiante, sexy, controlado, positivo, popular, proativo, ou menos ansioso, estressado, tímido, medroso, dependente, pessimista... Neste artigo, no entanto, o foco recai sobre um segmento particularmente problemático dentro do universo da autoajuda: $o$ aconselhamento parental.

Como é comum nesse filão editorial, a variedade de abordagens presente nesse viés da autoajuda é bastante ampla. De livros sobre como transformar seu filho em uma pessoa rica $^{6}$, feliz, inteligente, até obras voltadas a temáticas mais específicas como bullying, luto, gordofobia etc., o ramo do aconselhamento para pais parece ir muito bem, o que faz sentido, se pensarmos na contemporaneidade como um período marcado pela ansiedade. Se somos levados, a todo tempo, a refletir sobre o modo com que encaminhamos nossas trajetórias em busca de um ideal de vida "bem-sucedida", é fácil entender que tal inquietação se manifeste também na complexa missão de criar filhos (BECK, 1992).

Diante da extensa lista de temas minuciosamente abordados por esse ramo da autoajuda, chama a atenção a amplitude da proposta de Steve Biddulph: criar meninos 
e criar meninas. Nesse sentido, talvez seja interessante começar a apresentação dessas obras com a constatação de que, no discurso presente nesses livros, as crianças surgem como sujeitos "universais", ou seja, não há a preocupação de nenhuma especificidade quanto a contexto social, geográfico, étnico, racial... O único paradigma que parece contar na condução das obras é, de fato, o gênero. Os "filhos", "pais" e "mães" abordados na obra são tratados de maneira indiferenciada, embora fique evidente a escolha por um ethos bastante específico: a classe média branca.

Questões materiais são totalmente obliteradas nos livros: dentre os vários problemas que serão enfrentados pelos pais no desafio de criar filhos, aparentemente, não está a falta de dinheiro. A vida descrita pelas obras é uma em que o adolescente precisa ter seu próprio quarto individual, em que idas a restaurante, viagens, esportes e diversas atividades de lazer são encaradas com uma condição normal e necessária. A questão racial também é particularmente eloquente: ao longo das 406 páginas recheadas de fotos das duas obras, em apenas duas fotos são exibidas pessoas negras (as duas, de Criando meninos, exibem garotos de diferentes etnias em um ambiente escolar). É curioso que, em um livro com aspiração de afirmações de caráter universal, a escolha das imagens tenha seguido, ao contrário, um padrão tão específico, o que certamente não foi uma coincidência, tendo em vista que a própria temática racial não seja abordada em nenhum momento da obra ${ }^{7}$.

\section{Criando gênero: a construção da masculinidade}

\begin{abstract}
A construção dos gêneros e das sexualidades dá-se através de inúmeras aprendizagens e práticas, insinua-se nas mais distintas situações, é empreendida de modo explícito ou dissimulado por um conjunto inesgotável de instâncias sociais e culturais. É um processo minucioso, sutil, sempre inacabado. (LOURO, 2008, p. 18)
\end{abstract}

O primeiro livro publicado por Steve Biddulph com distinção de gênero foi o Criando meninos, cuja primeira edição data de 2002 (no original Raising boys: why boys are diferente - and how to

7 Dentre os vários assuntos tratados como potencialmente problemáticos na criação dos filhos, o racismo só é rapidamente mencionado duas vezes (em Criando meninos). A primeira em um texto assinado por um convidado sobre a importância da figura paterna: o autor, ao pegar uma carona com jovens latinos em Los Angeles e por isso acreditar estar arriscando a própria vida, surpreende-se ao constatar que os jovens "hispânicos" eram de boa índole e atribuiu o fato à forte presença do pai (ou seja, o racismo estava no próprio posicionamento do autor, o que não é problematizado). A segunda, quando o assunto é bullying, apresenta uma clara conexão com a lógica da cultura terapêutica: ao comentar, em um parágrafo, o comportamento dos chamados "valentões" da escola, a quem atribui uma postura de afırmar a "autoimagem declarando o que você não é", o autor afirma: "Daí se conclui que o caminho para acabar com o racismo e o sexismo, que são importantes problemas sociais do mundo moderno, passa pela autoestima dos garotos" (BIDDULPH, 2014, p. 137). 
help them become happy and well-balanced men). Na capa da versão brasileira, além do título Criando meninos, aparecem as frases "Para pais e mães de verdade!" e uma variação do subtítulo em inglês: "Por que os meninos são diferentes? O que o pai e a mãe podem fazer? Como torná-los homens equilibrados e felizes?". Apresentado como psicólogo, professor adjunto "honorário" da escola de Psicologia e Aconselhamento do Cairnmillar Institute, em Melbourne, Biddulph também ostenta na orelha do livro o curioso título de "Pai do Ano de 2000 na Austrália". Embora tenha uma formação bastante comum dentre os autores de autoajuda (muitos deles provenientes do campo psi), de fato a maior parte do discurso do livro é baseado na experiência do autor como pai. O tratamento de aspectos teóricos oriundos, por exemplo, de pesquisas acadêmicas é feito de maneira bastante aleatória ao longo do livro, como menções vagas e imprecisas do tipo "segundo pesquisas" ou "uma vez fizeram um estudo sobre"... Não há, portanto, uma preocupação em fundamentar os argumentos ${ }^{8}$ que são oferecidos pelo texto.

Logo no primeiro capítulo, Biddulph apresenta uma espécie de justificativa para trabalhar de maneira individualizada com a criação de meninos - e não de crianças de uma maneira geral. $\mathrm{O}$ argumento mais problemático, apresentado logo nas primeiras páginas e repetido várias vezes (de inúmeras formas) ao longo do texto, é o de que vivemos um momento complicado na criação de meninos, pois a masculinidade estaria em risco: "Hoje em dia, quando vemos nascer um menino, sentimos um aperto no coração - o que vai ser dele no futuro?" (BIDDULPH, 2014, p. 6). Os avanços conseguidos pelos movimentos feministas, sobretudo ao longo do século XX, são interpretados, nesta obra, como responsáveis por colocar os homens em um papel fragilizado, impotente, como se as mulheres de fato tivessem conseguido não só se igualar aos homens em termos de direitos e condições sociais, laborais, sexuais, mas tomado um protagonismo que teria como base o questionamento de tudo que estivesse associado ao universo do masculino. "Durante 30 anos, foi moda negar a masculinidade e dizer que meninos e meninas são iguais. (...) Estamos começando a entender como apreciar e não reprimir a masculinidade - qualquer que seja sua forma" (idem, p.7). 
O que parece motivar o incômodo do autor é um questionamento, que se configura sobretudo no campo das representações, sobre o papel da masculinidade hegemônica. O conceito é trabalhado por Connell (2005) a partir da noção de hegemonia proposta por Gramsci, em que as dinâmicas culturais são compreendidas como fatores fundamentais para a manutenção de poder por determinados grupos.

Como diversas culturas, em diferentes tempos, podem exaltar uma masculinidade em detrimento de outras, o conceito de masculinidade hegemônica vai concernir às configurações de práticas de gênero que sustentam as questões de legitimidade do patriarcado, que garantem (ou operam no sentido de garantir) o lugar de dominação aos homens e de subordinação às mulheres. 0 que não quer dizer que todas as masculinidades estejam inseridas(apesar de todos os homens serem beneficiados por essa lógica) ou que tais indivíduos detentores de poder institucional e/ou grandes fortunas sejam exemplares das normas de gênero em suas vidas pessoais. Ainda assim, o mais comum é que se estabeleça um modelo hegemônico quando esse conflui com o ideal cultural e com o poder institucional(CASTELLAN0 et al., 2018, p.7-8)
A discussão acadêmica (e também promovida pelos movimentos sociais ligados à luta feminista e LGBTQ) sobre a importância do aspecto socialmente construído do gênero é aqui apresentada como uma espécie de repressão dos aspectos "naturais" da masculinidade (e também da feminilidade). Em uma seção com o eloquente título "Notícia especial: as diferenças entre os sexos são reais!", o autor afirma:

\begin{abstract}
Nos últimos 30 anos, a teoria mais em moda foi aquela que garante que as diferenças entre meninos e meninas são impostas pelo condicionamento. Segundo esse pensamento, todas as diferenças de gênero vêm das roupas e brinquedos que damos às crianças. Pais bem-intencionados e muitas escolas de educação infantil e ensino fundamental passaram a insistir para que os meninos brincassem com bonecas, e as meninas, com blocos Lego ${ }^{9}$. A opinião reinante era que, se criássemos meninos e meninas do mesmo modo, os problemas e as diferenças entre os sexos desapareceriam (BIDDULPH, 2014, p. 33, grifo meu).
\end{abstract}

Por mais que insira uma breve contextualização dessa discussão, fazendo referências, por exemplo, aos objetivos imbricados nessa lógica, como "romper com os antigos estereótipos" (idem, p. 33) e destaque

9 É curioso que, 11 anos depois, ao escrever o livro Criando meninas, Biddulph tenha dedicado uma parte da seção sobre brinquedos para tratar do Lego e criticar a iniciativa da empresa em criar uma "versão feminina" do produto: "quatro amigas peitudas que cozinham, arrumam e decoram a casa, cuidam dos cabelos e fazem compras! Algum elemento limitador nessa restrita seleção?" (2015, p. 59), questiona. 
a importância do debate e das mudanças sociais subsequentes, o grande argumento do autor é que esse tipo de concepção sobre gênero está errada, e o peso social dos argumentos defendidos por autores ligados a essa posição desestimulavam toda "ideia de que pudesse haver diferenças biológicas intrínsecas entre meninos e meninas" (ibidem). O argumento final é que a "testosterona é fundamental para o comportamento dos meninos", e que o cérebro deles e delas "cresce de maneira diferente, o que afeta seu modo de pensar e agir" (idem, p. 34), ou seja, as diferenças são inatas e biológicas sim, o problema é que durante muitos anos foi "politicamente incorreto" negar isso.

Ainda na linha de apresentar o atual cenário como desfavorável aos homens, Biddulph destaca a seção "Os meninos não são inferiores - apenas são diferentes":

Germaine Greer destacou que os gênios em diversas áreas do conhecimento são homens em sua maioria (...). Em uma era antimasculina, é importante lembrar e mostrar aos meninos que foi um homem que inventou o avião e o carro, foram homens que lutaram nas guerras, construíram estradas de ferro e hospitais, descobriram remédios e participaram das grandes navegações, que fizeram tudo acontecer (BIDDULPH, 2014, p. 62, grifo meu).

É bastante sintomático que um momento cultural marcado por alguns avanços no sentido do questionamento dos papéis de gênero seja interpretado como uma "era antimasculina", em uma notável inversão histórica. "É preocupante ver como nós, homens, estamos por baixo", Biddulph (2014, p. 79) chega a afirmar. Dados atuais sobre a permanência de discrepância de salários entre homens e mulheres que exercem a mesma função, os elevados números de violência sexual e doméstica e a reiterada manutenção de estereótipos ligados à liberdade sexual feminina tornam difícil a compreensão da linha argumentativa do autor ${ }^{10}$.

Em Criando meninos, Biddulph apresenta o que chama de os três estágios da infância - do nascimento aos 6 anos (período em que o bebê/criança "pertence principalmente à mãe", dotada de um "jeito de cuidar da

10 Um possível argumento em defesa do autor seria relembrar sua nacionalidade. Embora certamente o contexto da Austrália seja bastante distinto do encontrado na América Latina, e no Brasil em particular, com suas relevantes intersecções de opressão de classe, raça e gênero, é importante apontarmos duas questões: a primeira é que seria ingênuo supor que as discrepâncias de gênero estejam totalmente resolvidas na Austrália e considerar que apenas países com piores índices sociais enfrentam problemas de sexismo. Em segundo lugar, vale ressaltar, como já o fizemos, o caráter pretensamente universal do discurso proferido pelos livros e o fato de eles serem vendidos em vários países do mundo. 
criança que costuma ser carinhoso, tranquilo e doce"(BIDDULPH, 2014, p.11). "Ele é um menino 'dela', embora o pai possa exercer um papel muito importante" (idem, p.9), afirma. Dos seis ${ }^{11}$ aos 13 anos, o autor define a fase como "Aprendendo a ser homem". O título poderia ser interpretado à luz das teorias contemporâneas sobre gênero associado à ideia de performatividade (BUTLER, 2003), ou seja, a partir da concepção de que a construção da identidade de gênero começa ainda na infância, momento em que moldamos nosso comportamento por meio das mensagens e exemplos que recebemos à nossa volta, quando começamos a nos empenhar nesses atos contínuos, repetitivos, que ajudam a nos enquadrar em categorias como "homem" e "mulher". O argumento, no entanto, não é esse. Logo nas primeiras linhas da seção, Biddulph afirma que é por volta dos seis anos de idade que "acontece uma grande mudança nos meninos. É como se, de repente, alguém apertasse um botão para 'ligar' sua masculinidade. Mesmo aqueles que não assistem muito à televisão começam a querer brincar com espadas, capas de Super-Homem, lutar e fazer barulho" (idem, p.14).
Como aponta Judith Butler (2003), o gênero é performativo: ele é construído discursivamente. Dessa forma, ela defende que os sujeitos são materializados a partir de normas performativas, construídas socialmente e necessariamente reiteradas. Discursos, para Foucault (2004), são práticas que sistematicamente "formam os objetos de que falam" e não se referem apenas a um conjunto de elementos, signos que remetem a um conteúdo específico, ou a uma representação. Assim, a performatividade entendida como um discurso refere-se à maneira pela qual um significante, em vez de simplesmente nomear algo que já existe, funciona para gerar o que aparentemente nomeia. É o que a filósofa americana chama de "interpelação fundante", que percebemos, por exemplo, quando a partir de um exame pré-natal é afirmado que o bebê é menino ou menina - mais do que a descrição de um corpo, tal declaração designa e define aquele corpo, trata-se de uma convocação, uma promessa, que precisa ser repetida por várias autoridades e em vários momentos da vida daquela pessoa, com a intenção de reforçar o efeito naturalizado (BUTLER, 1993; LOURO, 2013). 
Butler aproxima-se das contribuições de Foucault ao pensar nos efeitos de poder que são engendrados por esses discursos. A percepção do gênero como um artifício social, no entanto, antecede a obra de Butler. Anos antes de a filósofa tornar-se mundialmente conhecida por suas obras e formulações, Candace West e Don Zimmerman (1987) já haviam publicado o artigo "Doing gender", em que se dedicam a avaliar, justamente, o processo de construção do gênero a partir da percepção das reiterações cotidianas que são realizadas no sentido de criar uma relação naturalizada entre aspectos como sexo, identidade sexual e gênero. Nussbaum (2000) vai além e aponta em Johh Stuart Mill, filósofo britânico do século XIX, raízes de questionamentos que mais tarde ficariam muito associados aos pesquisadores da Teoria Queer:

\begin{abstract}
A desnaturalização do gênero estava presente já em Platão, e recebeu um grande impulso com John Stuart Mill, que afirmou em $A$ sujeição das mulheres [livro de 1869] que "o que hoje se chama a natureza das mulheres é uma coisa eminentemente artificial". Mill viu que as alegações sobre a "natureza das mulheres" derivam e fortalecem hierarquias de poder: a feminilidade é feita para ser o que quer que sirva à
\end{abstract}

causa de manter as mulheres em sujeição, ou, como ele diz, "escravizar suas mentes" (NUSSBAUM, 2000: 5) ${ }^{12}$.

A argumentação a respeito do gênero como construto social não é de fato nova e apareceu em reflexões sobre relações desiguais entre homens e mulheres em diferentes abordagens ao longo do tempo. Em um clássico discurso dedicado a denunciar a opressão racial, intitulado “E eu não sou uma mulher?", Sojourner Truth, também ainda no século XIX, discorre sobre a incongruência na fala de homens e autoridades sobre os cuidados e a atenção de que mulheres necessitariam: embora houvesse toda uma construção, à época, das mulheres como o "sexo frágil", seres indefesos que precisariam ser protegidos e cuidados, o mesmo discurso não era direcionado às mulheres negras, submetidas, no contexto da escravidão, a um regime de trabalho desumano. Conquanto não fosse exatamente esse o objetivo de Truth, sua crítica jogava luzes sobre um fato incontestável: a categoria mulher, utilizada por muito tempo como um ideal universal, era falha (RIBEIRO, 2017).

Ao longo do século XX, sobretudo a partir do que ficou convencionado como a segunda 
onda do movimento feminista ${ }^{13}$, nos anos 1960, diversas autoras também se dedicaram ao processo de desnaturalização dos papéis de gênero, chamando a atenção, muitas vezes pautadas por um pensamento estruturalista, como determinados mecanismos de poder dominados por homens marginalizavam e subordinavam não só as mulheres, mas também os homossexuais. Algumas das contribuições que versavam sobre essa temática vinham, inclusive, de fora das ciências humanas e sociais. A bióloga Anne Fausto Sterling, por exemplo, em uma meticulosa crítica às pesquisas experimentais que baseavam suas premissas na naturalidade das distinções convencionais de gênero, "mostrou quão profundamente as relações sociais de poder haviam comprometido a objetividade dos cientistas: Myths of Gender (1985) era um título apropriado para o que ela encontrou na biologia da época", comenta Nussbaum (2000, p. 6) ${ }^{14}$.

A construção dos papéis de gênero é apresentada de maneira bastante contraditória nos dois livros do nosso corpus, uma característica peculiar à autoajuda (CASTELLANO, 2018). Ao mesmo tempo em que afirma que a identidade de gênero é algo automático como "apertar um botão" ou atribua uma enorme importância a dados "naturais" como os hormônios, o autor destaca, a todo tempo, o valor do pai como um exemplo para o menino. Além disso, reforça, também amiúde, quão fundamental é uma espécie de pedagogia do gênero, como faz ao insistir, mais de uma vez, na relevância das "brincadeiras de luta" para que os meninos aprendam a canalizar a violência que é "intrínseca", "inata" a eles, ou em passagens como "dos seis aos 14 anos é a melhor oportunidade que o pai tem de construir as bases da masculinidade dele" (idem, p.22).

Para Judith Butler (2003), podemos pensar a noção hegemônica de gênero como historicamente forjada, a partir da concepção de que ele e é construído por meio de atos performativos. Gestos, práticas, atividades, comportamentos, maneirismos são repetidos, reforçados através da linguagem, e ajudam a demarcar os corpos dentro do estabelecido

13 "É importante ressaltar que, apesar de ser agrupado historicamente em ondas, o feminismo nunca teve uma agenda aceita universalmente e um único significado, uma clara e única ideologia comum, um manifesto único, uma organização central de líderes. As reivindicações do movimento são sempre relativas a contextos particulares, questões específicas e práticas pessoais. As feministas são, ao mesmo tempo, unidas por seu investimento em um conceito universal de igualdade e fraturadas pelos múltiplos objetivos e práticas pessoas que delineiam a concepção particular de justiça a que elas aspiram" (LEAL, 2015, p. 35)

14 No original: "showedhowdeeply social power-relationshadcompromisedtheobjectivityofscientists: MythsofGender (1985) wasanapttitle for whatshefound in thebiologyofthe time" 
binarismo de gênero. Embora se esforce para referir-se a uma masculinidade "primitiva", biológica e, portanto, a histórica, Biddulph reafirma um tipo muito particular de existência masculina. Nesse sentido, vale citar a seguinte passagem do livro Masculinities, de Connell:

A "masculinidade" não existe, exceto em contraste com a feminilidade. (...) nosso conceito de masculinidade parece ser um produto histórico bastante recente, com no máximo algumas centenas de anos. Ao falar de masculinidade, então, estamos "fazendo gênero" de uma maneira culturalmente específica. Isto deve ser levado em conta em qualquer pretensão em descobrir verdades trans-históricas sobre os homens e a masculinidade ${ }^{15}$ (CONNELL, 1995, p. 68).

Na seção "Ensinando os meninos a respeitar as mulheres", Biddulph comenta sobre o momento "marcante" em que os meninos se tornam fisicamente maiores do que a mãe. Segundo ele, a partir desse momento, "mais cedo ou mais tarde, o garoto vai tentar tirar vantagem disso" (2014, p. 77). O autor descreve então uma cena em que um jovem, Sam, de 14 anos, deixa de colocar a louça na máquina de lavar e responde "à mãe com certa falta de respeito, em voz baixa":

Agora vamos imaginar que essa é uma família de sorte. Primeiro, existe um pai. Segundo, ele está em casa. E terceiro, ele sabe o que tem que fazer. 0 pai de Sam está na sala dando uma olhada no jornal. Ele percebe o que se passa na cozinha. Essa é a deixa! Algo dentro dele espera por esse momento. Ele dobra o jornal, caminha decidido até a cozinha e se encosta na geladeira. Sam pode senti-lo chegar - é uma espécie de momento primitivo, hormonal. Ele percebe a mudança de poder. 0 pai olha longa e duramente para Sam e diz aquelas palavras consagradas pelo tempo - e que você provavelmente ouviu quando tinha 14 anos:-"Não fale com a sua mãe nesse tom de voz, ou você vai ter que ser ver comigo" (BIDDULPH, 2014, p. 78).

A necessidade da presença masculina como fundamental para impor o respeito à mulher (à mãe, nesse caso) já é uma ideia suficientemente problemática (e absurda), mas, além disso, transparecem algumas questões nesse trecho que gostaria de comentar. Em primeiro lugar, a menção à família "de sorte" como uma família que tem a figura paterna como um fato bom em si mesmo - os números gritantes ${ }^{16}$ de violência doméstica em

15 No original: "Masculinity" does not exist except in contrast with "femininity". (...) our concept of masculinity seems to be a fairly recent historical product, a few hundred years old at most. In speaking of masculinity at all, then, we are "doing gender" in a culturally specific way. This should be born e in mind with any claim to have discovered trans historical truths about manhood and the masculine.

16 https://g1.globo.com/jornal-nacional/noticia/2018/10/16/brasil-tem-mais-de-um-milhao-de-processos-de-violenciadomestica.ghtml Acesso em 21/12/2018. 
países como Brasil refutam, sozinhos, tal afirmação. Os diversos possíveis arranjos familiares são simplesmente ignorados. Famílias, por exemplo, formadas por duas mães ou dois pais, filhos criados pelos avós etc. não são sequer mencionadas em nenhuma das duas obras. A única exceção cogitada é o caso da mãe que cria o filho sozinha por motivo de separação ou viuvez - nesses casos, a ausência da figura masculina é fortemente lamentada e é indicado que a mãe busque algum homem que possa exercer esse papel, seja um tio ou um avô.

A estrutura patriarcal é reforçada de maneira bastante explícita - é em torno da figura do homem, do pai, que gravita a família: "Não é nada físico entre pai e filho, é uma espécie de força moral" (BIDDULPH, 2014, p. 78), reforça o autor. Ao mesmo tempo, ao abordar a necessidade de afeto do pai no trato com os meninos, Biddulph faz questão de ressaltar:

Alguns pais temem que, por darem carinho a seus filhos, eles se tornem "maricas", ou, talvez, gays. Não é assim. Na verdade, pode ser o contrário. Muitos gays ou bissexuais com quem conversei disseram que a falta de afeto paterno contribuiu para tornar a afeição masculina importante para eles (BIDDULPH, 2014, p. 17).

Ou seja, mais do que apenas "importante", o afeto do pai ao filho homem é quase uma questão de profilaxia... Na definição dos comportamentos masculinos a partir dos 14 anos, e mesmo antes, como já vimos, há uma forte atribuição de responsabilidade dos comportamentos considerados problemáticos (como a violência, a fissura por sexo ou a falta de responsabilidade) ao hormônio testosterona. Várias comparações são feitas em relação aos animais (observação de macacos, experimentos com ratos) para "provar" a influência da testosterona no comportamento dos machos (embora, como já comentei, nenhuma dessas pesquisas seja minimamente destrinchada).

Não se trata, aqui, de negar a materialidade que também constitui os corpos, mas de assumir que é no interior da cultura que tais características materiais adquirem significados e, mais do que isso, entender que tais significados passam por um processo de naturalização que é empreendido, dentre outras coisas, por objetos tais como os livros de autoajuda. Percepções sobre gênero e sexualidade, assim como nas demais temáticas, geram distinções que são produzidas através de processos discursivos e culturais. E essas distinções são ensinadas (LOURO, 2008).

Questões como a importância dada pelos homens a competição, classificação e hierarquia são diretamente atribuídas à influência desse hormônio, assim como a aptidão para a matemática e a capacidade de liderar ("Um 
garoto com altos níveis do hormônio dá um bom líder" idem, p.47), o que poderia levar à conclusão de que os homens são mais aptos aos cargos de chefia graças à produção de suas glândulas e não a um complexo processo histórico e social. Sobre os questionamentos a essa linha de pensamento, o autor afirma:

A ideia de que os hormônios afetam o comportamento dos meninos não é aceita por todos. Algumas biólogas feministas argumentam que os homens produzem testosterona por condicionamento, que resulta do modo como são criados. (...) Mas o ambiente só influencia o hormônio. Quem cria é a natureza - junto com o calendário interno dos meninos. Uma relação bem-sucedida com os meninos significa aceitar sua natureza e orientá-la para o melhor caminho. Tentar transformar meninos em meninas é um projeto destinado ao fracasso (BIDDULPH, 2014, pg. 43, grifo meu).

Em alguns momentos do texto, o autor comenta que existem outras pesquisas (nem todas encabeçadas por feministas, aparentemente) que associam as diferenças de base biológicas à criação e ao ambiente. Ou seja, mesmo aquelas características físicas, a princípio associadas apenas aos desígnios da natureza, podem ser influenciadas por aspectos culturais. Isso, no entanto, é pouco destacado no discurso de Biddulph, que prefere afirmar que não faz diferença se tais distinções são inatas ou adquiridas ${ }^{17}$. Não é difícil apontar outras problemáticas que aparecem quando objetivamos encarar comportamentos humanos apenas a partir de questões de ordem biológica. Algumas páginas a seguir já vemos um exemplo bastante eloquente sobre isso, quando Biddulph argumenta que sexo e agressividade são ligados "de algum modo", uma vez que "são controlados pelos mesmos centros no cérebro e pelo mesmo grupo de hormônios". A solução para que haja uma "separação entre os estímulos da violência e os do sexo" deveria vir, o que é curioso, do campo da cultura, evitando-se, por exemplo, a produção de filmes com enredos que misturem as duas temáticas: "filmes que ligam estupro e vingança não é uma boa ideia” (sic), conclui (BIDDULPH, 2014, p. 46).

A ênfase na questão física é recorrente em Criando meninos. O corpo masculino é apresentado como dotado de uma vitalidade e uma força incríveis, que precisam ser canalizadas para o fim "correto". Segundo Biddulph, o autocontrole é a "lição mais importante da vida de um garotinho" (BIDDULPH, 2014, p. 73). Segundo o livro, tal habilidade será requisitada, por exemplo, na preservação 
do casamento, já que "às vezes é preciso que os parceiros fiquem cara a cara, gritando a plenos pulmões" e "uma mulher só pode ter esse tipo de discussão franca e intensa com um homem junto do qual se sinta absolutamente segura. Ambos precisam ter a certeza de que ele não vai bater nela" (ibidem). "Essa é a medida do homem 'de verdade'. O homem de verdade é dono de si e de seu comportamento. Ele começa a aprender isso, pelo menos em parte, brincando de lutar no chão da sala com o papai ou o titio" (ibidem).

Mesmo quando aparentemente desenvolve um discurso que relativiza os papéis tradicionais de gênero, o texto acaba, em algum momento, promovendo ideias conservadoras e sexistas. Quando, por exemplo, fala sobre a importância de se ensinar os garotos a participarem do serviço doméstico, o texto começa com "Não é saudável um rapaz passar diretamente da companhia da mãe para a de uma esposa" (2014, p. 103), ou seja, a função doméstica deve ser naturalmente exercida pelas mulheres, mas é desejável que, durante um intervalo de tempo, o jovem possa, ele mesmo, realizar tais funções, até porque, como afirma mais à frente, "habilidades domésticas exercem sobre as mulheres a mesma atração de um carro esporte”, e "não existe a menor garantia de que o casamento resolva os problemas domésticos do seu filho" (idem, p. 104).
O script da vida heteronormativa tradicional o relacionamento heterossexual que desague no matrimônio - é a todo tempo reforçado e encarado como o caminho "normal" a ser seguido. Em um espaço confinado a uma página do livro, no sintomático capítulo "Desenvolvendo uma sexualidade saudável" (grifo meu), o autor comenta sobre transexualidade, em um texto intitulado "Meninos que querem ser meninas". O termo transexualidade não aparece de maneira direta, e o tema é tratado, como era de se esperar, de forma bastante superficial e problemática. Citando uma psicóloga que "acompanhou durante 15 anos três meninos com 'problemas de identidade sexual", o autor afirma que "as notícias são boas" (p. 114) - ou seja, de acordo com a profissional do campo psi, querer vestir roupas femininas ou "chegar a dizer que é uma menina" deve-se a um atraso no desenvolvimento e não a "um problema permanente" (ibidem). Embora afirme que o "problema" deve ser enfrentado com "ajuda e tolerância", o autor reforça a ideia de que isso nada tem a ver "com homossexualidade", de forma a confortar os pais que possam estar lendo (encarando, dessa forma, a homossexualidade como algo negativo) e reforçando a problemática noção de que a transexualidade seja algo necessariamente temporário e que os jovens estudados "ao chegar ao fim da adolescência, tinham se livrado do problema" (ibidem). 
Além do tratamento leviano sobre a transexualidade, há a problemática reiteração da sexualidade feminina infantilizada, a partir da concepção da identidade feminina como algo em processo, incompleto. As causas para tal "problema", seguindo a linha de todo o livro, estão centradas na figura do pai:

Alison Soutter [a psicóloga] não tem certeza das causas, mas os pais dos três garotos que estudou tinham doenças ou deficiências que os faziam exercer um papel passivo na família. Talvez o bom e afetuoso envolvimento do pai na vida familiar atue preventivamente, assegurando que os meninos considerem o papel masculino mais atraente (BIDDULPH, 2014, p. 114).

\section{Criando gênero: a produção do feminino}

Onze anos depois de publicar Raising boys (2002 - no Brasil, Criando meninos, 2014), Steve Biddulph lançou Raising girls (2013 - no Brasil, Criando meninas, 2015). A década que separa as duas publicações faz diferença na condução do discurso dos livros. É nítida, na versão voltada para as garotas, uma maior preocupação do autor ao tratar das questões que envolvem gênero e sexualidade, o que se deve certamente tanto a um contexto de maior atenção em relação a essas temáticas quanto a uma posição "desconfortável" do autor, um homem, em escrever sobre a criação de mulheres: seu "lugar de fala" é justificado logo na abertura do livro, quando explica que, depois de 20 anos atuando como especialista em "meninos e homens" (e pai de um garoto de 7 anos), o nascimento de sua filha o fez atentar para uma nova realidade:

\begin{abstract}
As meninas iam bem. Então, em meados da década de 2000, começaram a mudar. Viu-se uma queda súbita e marcante de seu equilíbrio mental, primeiro nos Estados Unidos, espalhando-se em seguida pelo mundo inteiro. Problemas como distúrbios alimentares e autoflagelação antes extremamente raros, eram relatados em todas as escolas e quase todas as ruas. E mais: meninas comuns mostravam-se estressadas e deprimidas como nunca" (BIDDULPH, 2015, p. 6-7).
\end{abstract}

O cenário desalentador descrito por Biddulph, além de aleatório (quais são, novamente, os dados que permitem que ele afirme, por exemplo, que as mulheres hoje estão mais deprimidas do que nunca?), serve de leitmotiv para a obra: se, no caso dos meninos, os maiores desafios, que parecem vir "de dentro", são quimicamente estimulados, tais como os impulsos provocados pela ação da testosterona, no caso das meninas, pais e mães zelosos devem ficar atentos às ameaças que a cultura impõe à sua saúde mental.

Logo no primeiro capítulo, o autor introduz a história de duas jovens de 17 anos (Kaycee e Genevieve), que serão retomadas ao final do livro. Kaycee, segundo nos conta Biddulph, "usa maquiagem cuidadosamente aplicada e roupas moderníssimas"; no entanto, "há 
alguma coisa no jeito dela. A expressão cansada. O ceticismo". Aos 14 anos, durante uma festa de aniversário, em que "quarenta ou cinquenta jovens de idades variadas passaram a noite na casa, com bebida à vontade e nenhum adulto por perto: música alta, falta de controle, caos" (BIDDULPH, 2015, p. 9), Kaycee teve sua primeira experiência sexual com um jovem de 17 anos: "Tudo aconteceu mais depressa e com menos carinho do que Kaycee havia imaginado (...). Embotado pela bebida, o cérebro dela não funcionava muito bem, mas conseguiu perceber a mudança de sentir-se especial, o centro das atenções, para a sensação de ter sido humilhada, invadida, desconsiderada" (BILDDUPH, 2015, p. 9). A cena descrita é bastante conhecida do público acostumado aos filmes de high school: a menina perde a virgindade para o galã da escola, que ato contínuo a abandona, sem consideração, e vai contar sua façanha para os amigos. A menina, aos prantos, é amparada por uma amiga.

A história é apresentada como fundamental na construção da vida de Kaycee, que depois de um momento de "ódio aos homens", passou a "tomar a iniciativa da conquista e a estabelecer regras". "Aos 17 anos (...) já havia praticado sexo com sete rapazes diferentes. Ou talvez fossem oito, já que em uma noite de bebedeira, houve certa confusão" (BIDDULPH, 2015, p. 10). Embora ninguém, obviamente, deseje que a filha (ou filho) tenha uma primeira experiência sexual marcada pelo desrespeito, é interessante notar que essa preocupação só aparece no livro dedicado às meninas e que também não haja nenhum comentário sobre o comportamento nocivo do rapaz envolvido, e a história sirva, no fundo, para questionar a conduta sexual da jovem. Da mesma forma, a necessidade de comentar o número de parceiros sexuais da moça aos 17 anos não encontra paralelo no livro Criando meninos. Não é muito difícil imaginar o porquê.

Embora se esforce em alguns momentos a se mostrar mais "progressista", o tom conservador do discurso a respeito da sexualidade feminina e dos papéis de gênero é bastante evidente ao longo de todo texto e explícito em passagens como "as garotas de hoje cultivam os mesmos desejos e sonhos das garotas de antigamente" (BIDDULPH, 2015, p. 11). Além de conservador, o discurso é bastante apocalíptico, sobretudo a respeito do papel da mídia, instituição que recebe muita atenção nas duas obras, em um tom que faria Adorno e Horkheimer (1995) acharem que ele estava indo longe demais (sobretudo para um texto escrito em 2013). Ao comentar, por exemplo, o fato de que "o ganancioso mundo corporativo percebeu que as meninas (...) representam um alvo fácil, as empresas calcularam enormes lucros que teriam ao explorar as ansiedades daquele grupo" (BIDDULPH, 2015, p. 12), o autor aponta 
como consequência: "[elas] lotam como nunca as clínicas de doenças mentais, as delegacias de polícia e o setor de emergência dos hospitais" (ibidem).

Em Criando meninos, Biddulph afirma que "a mídia frequentemente apresenta homens como estupradores, assassinos ou fazendo papel de trouxas. Então, é muito fácil para o garoto sentir-se mal com o fato de ser homem" (2014, p. 92). Além disso, em relação à vida sexual, a mídia é acionada para ser apontada como possível responsável por ataques de violadores, pois, segundo o autor, vende a mensagem do "olhe, mas no toque", em videoclipes de cantoras sensuais (que caracteriza como "pornô soft"), em revistas para adolescentes, uma "tremenda provocação [que] alimenta uma raiva, de certo modo bastante válida e intensamente carregada de um aspecto sexual" - e se coloca como revoltado contra a "utilização, em anúncios, de imagens que agarram nossos filhos pelo pênis" (2014, p. 118).

A outra história narrada no início de Criando meninas é a de Genevieve, também de 17 anos. A primeira grande diferença dela para Kaycee é que Genevieve não namora: "Ela gostaria de namorar, mas prefere agir com cautela. Sabe que os amores jovens nem sempre são fáceis" (BIDDULPH, 2015, p. 12). Quando estava envolvida com um menino que a pressionou a fazer sexo, Genevieve não só negou como conversou longamente com a mãe sobre o assunto:

"Enquanto muitas meninas preferem conversar sobre esses assuntos com as amigas, Genevieve discutia com a mãe os pensamentos mais íntimos" (idem, p. 13). De maneira bastante esquemática (e moralista), as duas histórias servem para ilustrar como a filha do leitor deve se comportar.

Assim como afirma que a masculinidade dos meninos acontece do nada, como o apertar de um botão, Biddulph garante que "a garota se transforma em 'mulherzinha' da noite para o dia" (2015, p. 24). O autor dá muita ênfase ao fato de que as mulheres amadurecem mais cedo do que os homens e, para isso, lança mão de "pesquisas" e "estudos" sobre o funcionamento do cérebro para afirmar que as causas são puramente biológicas: "O desenvolvimento do cérebro feminino completa-se anos antes do desenvolvimento do cérebro masculino, que só acontece lá pelos 20 e poucos anos. É como se a natureza dissesse a elas: 'É melhor você se adiantarem. Vão precisar de juízo!"” (2015, p. 24).

É interessante observar que a despeito de afirmar, em vários momentos dos dois livros, que as mulheres desenvolvem-se mais cedo que os homens em relação à cognição e mesmo no sentido da puberdade, a partir da menstruação e do desenvolvimento dos órgãos 
reprodutores, o princípio da vida sexual é sempre encarado como um tabu maior no caso delas, o que não faz sentido, tendo em vista que fisiológica e mentalmente, se levarmos em consideração o discurso dos livros, elas estão mais "preparadas" do que eles para iniciar esse lado da vida pessoal. É sobre elas, no entanto, que recaem as preocupações sobre a hora "certa" de começar a fazer sexo, sem contar o emprego bastante questionável de termos como "ceder" como sinônimo de ter relações sexuais, o que reforça a ideia de que a mulher, ao se envolver sexualmente em uma relação heterossexual, está, na verdade, querendo agradar ao homem e não dando vazão à própria libido. Mais à frente, no entanto, seguindo a linha contraditória que já indicamos, há um box intitulado "As meninas e o desejo - o que ensinar?", em que o autor afirma: "As garotas sentem tanto desejo quanto os garotos. Cabe aos pais - mães, em especial - dizer à filha, antes que a ansiedade se instale, que sexo é bom e que ela vai gostar" (BIDDULPH, 2015, p. 159).

No livro dedicado às meninas, a relação entre natureza e cultura aparece de forma mais complexa (e também contraditória). Ao mesmo tempo em que reafirma a todo tempo as diferenças fundamentais (e inatas) entre homens e mulheres, sem as quais seus próprios livros não fariam sentido, o autor destaca, com exemplos bastante convincentes, a característica de construto social de algumas noções, tais como a maior aptidão dos meninos para os números e as meninas para os sentimentos (embora em outras passagens deste e do outro livro insista que tais direcionamentos são comandados apenas pelo "cérebro" e pelos hormônios):

Às vezes inconscientemente impomos limites às meninas. Um recente estudo sobre 0 modo como falamos às crianças pequenas concluiu que, sem perceber, os pais mudam de foco e de assunto conforme o sexo dos filhos. Vamos comparar:

Ao menino: "Olhe! Três coelhos ali no campo!"

À menina: "Olhe, os coelhinhos. Não são BONITINHOS?"

Ao menino: "Uau! Você fez uma torre com DEZ BLOCOS!"

À menina: "Que LINDA torre você fez!"

(...) Sem perceber, eles favorecem o espírito prático dos meninos, enquanto orienta, as meninas para a emoção (BIDDULPH, 2015, p. 47).

A heteronormatividade é bastante evidente ao longo dos dois livros. A homossexualidade ocupa um box em cada uma das obras, de forma a deixar evidente a condição de algo fora do padrão. Utilizo o conceito de heteronormatividade a partir da percepção de que a heterossexualidade é apresentada como um caminho "natural" e "correto", e qualquer outra manifestação do desejo para além da 
relação direta (e construída) a respeito da vinculação sexo, identidade sexual e sexualidade é vista como desvio. Durante muito tempo, a temática da heterossexualidade não se configurou como uma preocupação central dos estudos de gênero. Foi principalmente a partir do desenvolvimento da chamada Teoria Queer que essa questão passou a figurar como fundamental na compreensão de uma série de fenômenos no campo da sexualidade, inclusive na manutenção de opressões em relação às mulheres (RICH, 1980; SCHILT, WESTBROOK, 2009).

A mudança do objeto de análise das margens (mulheres, homossexuais) para 0 centro (homens, heterossexuais) permitiu a teorização da heteronormatividade - 0 conjunto de práticas culturais, legais e institucionais que mantêm suposições normativas de que existem dois e apenas dois gêneros, que o gênero reflete o sexo biológico e que somente a atração sexual entre esses gêneros "opostos" é natural ou aceitável. ${ }^{18}$ (SCHILT, WESTBROOK, 2009, p. 441)

As seções dedicadas ao tema recebem o mesmo título nas duas obras: "E se o filho for homossexual?" e "E se sua filha for lésbica?". É interessante, nesse sentido, perceber a manifestação não só do binarismo de gênero (homem/mulher), mas também de sexualidade (hétero/homossexual). Se, a despeito das polêmicas criadas em torno da ideia de pós-modernidade, aceitarmos que os sujeitos hoje, tal como afirma, por exemplo, Hall (2004), passa por uma fase de descentramento da identidade, é interessante notarmos quão "modernos" são os horizontes de sentido propostos em livros como esses, em que não só a heterossexualidade é entendida por norma, como a homossexualidade é percebida como uma condição concreta e definitiva em termos (apenas) de "ser" ou "não ser". Como comenta Louro, "o desafio maior talvez seja admitir que as fronteiras sexuais e de gênero vêm sendo constantemente atravessadas e - o que é ainda mais complicado admitir - que o lugar social no qual alguns sujeitos vivem é exatamente a fronteira" (2008, p. 21).

Em Criando meninos, o tema ocupa uma página e meia (de 168) e, em Criando meninas, quatro (de 238). Há uma certa evolução entre as duas obras, e, nesse sentido, é importante lembrar a diferença de mais de uma década entre as duas publicações. No primeiro livro, o discurso girava em torno da aceitação, na 
linha do "é preciso aceitar, não adianta ficar pensando 'onde foi que erramos"'. Havia uma ênfase, também, no fato de que a descoberta da homossexualidade do filho implicava a destruição de "várias esperanças queridas" (2014, p. 124), tais como ver o filho casado e ter netos (embora não haja uma relação tão direta entre esses temas e a homossexualidade, apenas na medida em que o casamento tal como concebemos ainda hoje é uma instituição basilar da sociedade heteronormativa, na qual se enquadram, inclusive, muitos casais homossexuais).

Em Criando meninas já há uma preocupação com a utilização de uma linguagem mais elaborada em relação ao assunto, tal como usar o termo "LGBT", algo que não constava no primeiro livro. Embora inicie o texto incentivando os pais a compreenderem e a apoiarem as filhas lésbicas, o autor cita de maneira aleatória "estudos" que indicam que algumas mulheres "procuram se relacionar com pessoas do mesmo sexo como reação a dolorosas experiências com homens" (BIDDULPH, 2015, p.129). Essa é uma ideia que reforça um dos estereótipos mais difundidos (e problemáticos) sobre mulheres lésbicas: mulheres frustradas, ou que ainda não conheceram "um homem de verdade", forma de preconceito que não só nega a potência do desejo feminino fora do escopo da heteronormatividade, como fundamenta parte da violência dirigida às mulheres lésbicas (na forma, por exemplo, do estupro "corretivo").

\section{Considerações finais}

Ao comentar a icônica frase de Simone de Beauvoir com a qual abro este artigo, Louro (2008, p. 18) a define como uma espécie de "gatilho provocador de um conjunto de reflexões e teorizações, exuberante e fértil, polêmico e disputado, não só no campo do feminismo e dos estudos de gênero, como também no campo dos estudos da sexualidade". É certo que, desde o final da década de 1940, quando a autora francesa publicou O segundo sexo, até os dias atuais, muitas coisas mudaram, e o próprio sentido da frase foi expandido, a partir da compreensão de que também a masculinidade é objeto de uma construção constante e cuidadosa. "Fazer de alguém um homem requer, de igual modo, investimentos continuados. Nada há de puramente 'natural' e 'dado' em tudo isso: ser homem e ser mulher constituem-se em processos que acontecem no âmbito da cultura (IBIDEM;WEST, ZIMMERMAN, 1987).

"Mesmo antes do nascimento do nosso filho, já fazemos um mapa para a vida dele. E os sonhos são sempre conservadores: carreira, casamento e netos para sentar no colo!", afirma Biddulph (2014, p. 124) em uma passagem de Criando meninos em que 
expõe, de maneira muito evidente, como a construção de gênero é um processo cuja elaboração sistemática dá-se antes mesmo da existência plena do sujeito como um ser independente. Percebemos, dessa forma, uma contradição bastante eloquente relativa à discussão sobre os aspectos biologizantes e naturalizantes das concepções de gênero e sexualidade. Embora a ala de pensamento mais conservador, frequentemente amparada em um discurso religioso, enfatize a característica imanente e "dada" da relação entre genitália, gênero e sexualidade, percebemos um esforço descomunal, empenhado desde a mais tenra infância, no sentido de direcionar os corpos a um destino que seria do campo do inevitável. Se homens são geneticamente programados para a virilidade, para o desejo ao corpo feminino, para a racionalidade, a força e o desprendimento, e as mulheres nascem biologicamente determinadas ao apego ao lar, à docilidade, à ternura, à atração pelo corpo masculino, aos anseios pela constituição de uma família e à maternidade, não haveria a necessidade de um cuidadoso direcionamento desses desejos, anseios e aspirações desde o momento que antecede o próprio nascimento, a partir das expectativas geradas na família - e materializadas em objetos de decoração do quarto do bebê. A propósito, a capa de Criando meninas é rosa e a de Criando meninos é azul.
Nesse sentido, entendo a literatura de autoajuda de aconselhamento parental como parte de um grande dispositivo social, aqui em seu viés mais nitidamente cultural/midiático, de reafirmação dos papéis de gênero a partir do incentivo (e também da naturalização/ ocultamento) à performatividade desses mesmos gêneros (BUTLER, 2003). Se entendemos a autoajuda como um viés cultural que contribui para conformar nosso ideal de vida a partir da opinião de autoproclamados especialistas que nos ajudam a entender o que é aceitável/desejável/esperado em termos de atitudes, estilos de vida, aparência etc., podemos apontar a autoajuda também como criadora de gênero, no sentido de favorecer algumas performances de gênero e sexualidade em detrimento de outras. É significativo, por exemplo, que a maior parte da autoajuda voltada para mulheres adultas enfatize a maternidade como uma realidade quase inescapável e o casamento heterossexual como "o" destino final de uma vida feliz. O problema, aparentemente, está na criação e ampla divulgação de uma norma:

A norma, ensina-nos Foucault, está inscrita
entre as "artes de julgar", ela é um princípio
de comparação. Sabemos que tem relação
com o poder, mas sua relação não se dá
pelo uso da força, e sim por meio de uma
espécie de lógica que se poderia quase
dizer que é invisível, insidiosa (EWALD,
1993). A norma não emana de um único
lugar, não é enunciada por um soberano, 
mas, em vez disso, está em toda parte. Expressa-se por meio de recomendações repetidas e observadas cotidianamente, que servem de referência a todos. Daí por que a norma se faz penetrante, daí por que ela é capaz de se "naturalizar" (LOURO, 2008, p. 22).

Em um provocativo artigo dedicado a questionar o pensamento de Judith Butler, Martha Nussbaum (2000), filósofa norte-americana, questiona até que ponto as contribuições, por vezes "esotéricas" e "pernósticas", de sua conterrânea auxiliam, de fato, no avanço do debate sobre as lutas das mulheres "reais", em seus desafios cotidianos, de ordem material (boa parte do argumento é construída na comparação com abordagens mais tradicionais do campo dos Estudos Feministas). Embora tendamos a concordar com Nussbaum a respeito das limitações (e incoerências) no argumento de certos autores vinculados à Teoria Queer, em especial aqueles mais devotos a determinadas correntes do pensamento pós-moderno, acreditamos que algumas de suas formulações podem render prolíficas investigações quando aplicadas ao estudo de objetos concretos que povoam nosso cotidiano e, consequentemente, nosso imaginário. E é nesse sentido que percebemos como "produtivo" mobilizar as contribuições aqui citadas na busca pela compreensão dos significados culturais delineados pela autoajuda de aconselhamento parental.
Perceber a literatura de autoajuda e outros artefatos culturais oriundos da cultura de massa como "desimportantes" é não atentar para o fato de que, independentemente da "qualidade" desses produtos (o que por si só rende uma discussão interminável), eles importam. Importam na medida em que ajudam a consolidar uma norma, a partir de práticas sociais normalizadoras, que Teresa de Lauretis (1994) denominou como "tecnologias de gênero"; importam no sentido pretendido por Hall (2016) quando afirma que as lutas pelo poder são sobretudo simbólicas e discursivas. Não se trata de negar a existência de questões de ordem física e biológica, mas de entender que elas se tornam socialmente funcionais a partir do momento em que são interpretadas pela cultura. Se desejamos disputar os sentidos atribuídos ao gênero e a seus correlatos papéis, devemos refletir sobre todas as esferas em que esses sentidos são produzidos, e acredito que o olhar sobre a infância e a construção social que ocorre desde o início da vida seja um lócus interessante de observação.

\section{Referências}

ADORNO, Theodor W, HORKHEIMER, Max. A dialética do esclarecimento. Rio de Janeiro: Jorge Zahar, 1995.

BEAUVOIR, Simone de. 0 segundo sexo volume 2: a experiência vivida. São Paulo: Difusão europeia do livro, 1967. 
BECK, Ulrich. Risk society: towards a new modernity. Londres: Sage, 1992.

BUTLER, Judith. Problemas de gênero: feminismo e subversão da identidade. Rio de Janeiro: Civilização Brasileira, 2003.

Bodiesthatmatter. Onthediscursive

limites of 'sex'. Nova York/Londres:

Routledge, 1993.

CASTELLANO, Mayka. Vencedores e

fracassados: o imperativo do sucesso na cultura da autoajuda. Curitiba: Editora Appris, 2018.

CASTELLANO, Mayka et al. "TV de qualidade é TV masculina?": controvérsias de gênero no debate sobre dramas de prestígio. Anais do $7^{\circ}$ Encontro de GTs de Pós-Graduação do Comunicon ESPM/SP, 2018.

CONNELL, Raewyn. Masculinities. California: Universityof California Press, 1995.

FOUCAULT, Michel. História da sexualidade. I. A vontade de saber. Rio de Janeiro: Graal, 1988.

. A arqueologia do saber. Rio de Janeiro: Forense Universitária, 2004.

HALL, Stuart. A centralidade da cultura: notas sobre as revoluções de nosso tempo. Educação \& Realidade. v. 22, n. 2, 1997.

A identidade cultural na pósmodernidade. Rio de Janeiro: DP\&A, 2004. .Cultura e representação. Rio de Janeiro: PUC-Rio, 2016.

LAURETIS, Teresa de. A tecnologia do gênero. In: HOLLANDA, Heloísa Buarque de. Tendências e impasses. $O$ feminismo como crítica da cultura. Rio de Janeiro: Rocco, 1994.
LEAL, Tatiane. A mulher poderosa: construções da vida bem-sucedida feminina no jornalismo brasileiro. Dissertação de mestrado em Comunicação e Cultura. Escola de Comunicação da UFRJ, 2015.

LOURO, Guacira Lopes. Gênero e sexualidade: pedagogias contemporâneas. Pro-Posições, v. 19, n. 2 (56), 2008.

. Uma sequência de atos. Revista Cult, São Paulo, n.185, p. 31-34, 2013.

QUEIROZ, Nana. "Não é só o gênero que é socialmente construído, o sexo biológico também". Entrevista com a bióloga americana Anne Fausto-Sterlling, 2016. Disponível em: https://www.geledes.org.br/nao-e-so-ogenero-que-e-socialmente-construido-o-sexobiologico-tambem/

RIBEIRO, Djamila. O que é lugar de fala? Belo Horizonte: Letramento, 2017.

RICH, Adrienne. Compulsory heterosexuality and lesbian existence. Signs: Journal of Women in Culture and Society, n. 5, v. 4, p. 631-660, 1980.

SCHILT, Kristen; WESTBROOK, Laurel. Doing gender, doing heteronormativity. Gender normals, transgender people, and the social maintenance of heterosexuality. Gender\&Society, v. 23, n. 4, p. 440-464, 2009. WEST, Candace, ZIMMERMAN, Don. Doing gender. Gender\&Society, v. 1, n. 2, p. 125151, 1987. 


\section{Raising gender: the discourse on raising boys and girls in parenting self-help}

Creandogénero: el discursosobre la creación de niños y niñas en la autoayuda de aconsejamiento parental

\begin{abstract}
In this paper, I analyze the discourse on gender identity presented in Steve Biddulph's books "Raising Boys" (2014) and "Raising Girls" (2015), self-help classics for parental counseling. Based on post-structuralist discourse analysis, I investigate how gender appears in the formulations of these books and how such ideas reflect cultural expectations and concerns about raising children in the contemporary world, taking into account the respective gender roles in a society marked by binarism and heteronormativity.
\end{abstract}

\section{Keywords}

Gender identity. Self help. Discourse analyses.

\section{Resumen}

Eneste artículo, analizo el discurso sobre identidad de género presentado en los libros "Creando niños" (2014) y "Creando niñas" (2015), de Steve Biddulph, clásicos de la autoayuda de aconsejamiento parental. Amparadaen el análisis de discurso de inspiración post-estructuralista, investigo de qué modo el género apareceen las formulaciones de esos libros y de qué forma tales ideas reflejan expectativas e inquietudes culturales acerca de la creación de los hijos en la contemporaneidad, teniendo en cuenta los respectivos papeles de géneroen una sociedad marcada por el binarismo y la heteronormatividad.

\section{Palabras clave}

Identidad de género. Autoayuda. Análisis de discurso.

\section{Mayka Castellano}

Doutora em Comunicação e Cultura pelo Programa de PósGraduação em Comunicação e Cultura da Universidade Federal do Rio de Janeiro. Professora do departamento de Estudos Culturais e Mídia e do Programa de PósGraduação em Comunicação da Universidade Federal Fluminense. | E-mail: maykacastellano@gmail.com ORCID: http://orcid.org/0000-0003-4401-5979 